Available online on 15.01.2021 at http://jddtonline.info
O 2011-21, publisher and licensee JDDT, This is an Open Access article which permits
unrestricted non-commercial use(CC By-NC), provided the original work is properly cited
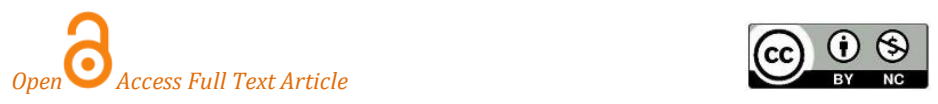

Research Article

\title{
Formulation and Evaluation of Liposome by Thin Film Hydration Method
}

\author{
Mahesh Umbarkar1*, Swapnil Thakare², Tanaji Surushe³, Amol Giri, Vaibhav Chopade ${ }^{5}$ \\ ${ }^{1}$ Department of Pharmaceutics, R.C. Patel Institute of Pharmaceutical Education and Research, Shirpur - 425 405, Maharashtra, India \\ 2 Department of Pharmaceutics, R.C. Patel Institute of Pharmaceutical Education and Research, Shirpur - 425 405, Maharashtra, India \\ ${ }^{3}$ Department of Pharmaceutical Chemistry, MUP's Collage of Pharmacy, Degaon - 444 506, Maharashtra, India \\ ${ }^{4}$ Department of Pharmaceutics, Samarth collage of Pharmacy, Deulgaon Raja - 443 204, Maharashtra, India
}

${ }^{5}$ Department of Pharmaceutics, R.C. Patel Institute of Pharmaceutical Education and Research, Shirpur - 425 405, Maharashtra, India

\begin{tabular}{l} 
Article Info: \\
\hline Article History: \\
Received 19 Oct 2020; \\
Review Completed 21 Dec 2020 \\
Accepted 30 Dec 2020; \\
Available online 15 Jan 2021
\end{tabular}

Cite this article as:

Umbarkar M, Thakare S, Surushe T, Giri A, Chopade $\mathrm{V}$, Formulation and Evaluation of Liposome by Thin Film Hydration Method, Journal of Drug Delivery and Therapeutics. 2021; 11(1):72-76

DOI: http://dx.doi.org/10.22270/jddt.v11i1.4677

*Address for Correspondence:

Mahesh Gajanan Umbarkar, Department of

Pharmaceutics, R.C. Patel Institute of Pharmaceutical

Education and Research, Shirpur - 425 405,

Maharashtra, India

\begin{abstract}
Liposomes are the most advance formulation for targeting and controlled drug delivery system. These liposomes are generally administered by intra-venous route. In this work the liposome was prepared by using thin film hydration method. The formulated liposome is evaluated or characterised by using zeta sizer, Encapsulation efficiency, Entrapment efficiency, In vitro drug release. Main things are drug which are used for formulation of liposome was Diclofenac sodium, it having antiinflammatory and anti-pyretic effect. The Diclofenac sodium having several adverse effects, such as depression of renal function, Liver failure for repeated administration, Local mucosal irritation, gastritis. To avoid this adverse effect Diclofenac sodium are incorporate in liposomal formulation. By formulating liposomal formulation, the bioavailability of Diclofenac sodium increase. In conventional dosage form bioavailability of diclofenac sodium is $50 \%$. But in liposomal formulation bioavailability of this drug increase. The final result includes that diclofenac liposome formulation shows more sustained and prolong antiinflammatory activity.
\end{abstract}

Keywords: Diclofenac sodium, Liposome, Anti-inflammatory activity.

\section{INTRODUCTION:}

The liposome is tiny bubble and is made up of same material as cell membrane. The name of liposome is derived from two Greek words "Lipos" means Fat and "soma" means body. The membrane of phospholipid is having ability to self-assemble into tiny bilayer sphere. If single layer sphere is formed then called as micelles. ${ }^{1}$ Liposome carries numerous molecules in pharmaceutical industry and cosmetic, these are used in cosmetic preparation also. The liposome is carrying both hydrophilic and hydrophobic drug also. ${ }^{2}$ The liposomal preparation is also useful for oral local treatment. ${ }^{3}$ These liposomes are having different types according to their structure such as Large Unilameller Vesicle (LUV), Multilamellar Vesicle (MLV) and Small Unilameller Vesicle (SUV). Liposomes are colloidal and small vesicular structure of lipidic bilayer. The main component of liposomal structure is cholesterol and non-toxic phospholipid. The liposome is having different property by changing lipid concentration, amount of cholesterol, method of preparation, charge present on surface and size of liposome. The unsaturated phosphatidylcholine species shows the less stable and more permeable bilayer structure of liposome. Whereas, saturated phospholipid is form more rigid and less permeable structure of liposome. Generally, liposome is having structure spherical in nature and size start from $30 \mathrm{~nm}$ to several micrometre size. The polar head of lipid are oriented toward the internal and external aqueous phase and nonpolar tail of bilayer to each other. There are many factors which are affecting on liposomal formulation or preparation such as temperature, molecular shape, drug and their nature, type of phospholipid and their nature. Liposomes are vesicle in which nutrient and many pharmaceutical drugs incorporate. These liposomes are having several advantages but disadvantage also having such as it shows oxidation due to lipid as major component. 4

There are several routes which are available for administration of liposome such as oral, Parenteral and Topical. The liposomal formulation is having targeted drug delivery action; due to that liposome are novel dosage form for administration many drugs in it. These liposomal structures are highly lipophilic in nature; these are made up of phospholipid. The topical absorption of liposome is taking place very easily due to lipidic nature. Many liposomal formulations are used for topical administration. The 
biodegradation of liposome is easily taking place. These liposome formulations more advance formulation for administration of drug. The topical formulation of liposome which are act as local anaesthetics. The Diclofenac sodium is the NSAID drug, which is widely used for antipyretic, antiinflammatory, and analgesic also for joint stiffness activity. Diclofenac sodium are having short half-life about 1-2 hr. In conventional dosage form diclofenac sodium are reaches in blood circulation as about only $50 \%$ but in liposomal formulation the bioavailability of diclofenac sodium increase. Due to that more adverse effect of diclofenac sodium such as depression of renal function, liver failure for repeated administration, local mucosal irritation and gastritis, hence drug is incorporated into liposome. Due to liposome incorporating the adverse effect reduces. The antiplatelets action is not appreciable due to sparing of COX-I. It is having 99\% protein bound and excreted in both urine and bile. The particle size of liposome is in range of nanometre, these nanometric sizes of liposome and its lipidic nature increase the penetration property, due to that two things the bioavailability of this drug increase. When the liposomal formulation is administered by parenteral routes then first pass metabolism is also reducing. 5

\section{MATERIAL AND METHOD}

Table-1: List of material used for the study

\begin{tabular}{|l|l|l|}
\hline Sr.No & Ingridients & Supplier \\
\hline 1 & Diclofenac Sodium & $\begin{array}{l}\text { Alkha Pharmaceutical, } \\
\text { Hyderabad }\end{array}$ \\
\hline 2 & Soya lecithin & Sami Lab Lmt. Bangalore \\
\hline 3 & Cholesterol & Laboratory \\
\hline 4 & Rotary flash evaporator & KNF \\
\hline 5 & Ultra-centrifugation & Beckman Coulter \\
\hline 6 & Zeta sizer & Malvern \\
\hline 7 & Magnetic stirrer & REMI \\
\hline 8 & Weighing Balance & Jepson's \\
\hline
\end{tabular}

Drug Profile: -<smiles>O=C(O)Cc1ccccc1Nc1c(Cl)cccc1Cl</smiles>

Structure of Diclofenac Sodium

The Diclofenac sodium is the NSAID drug, which is widely used for antipyretic, anti-inflammatory, and analgesic also for joint stiffness activity. Diclofenac sodium are having short half-life about 1-2 hr. In conventional dosage form diclofenac sodium are reaches in blood circulation as about only $50 \%$. The antiplatelets action is not appreciable due to sparing of COX-I. It is having 99\% protein bound and excreted in both urine and bile. These are having water soluble in nature. ${ }^{5}$

\section{Preperation of Liposome: -}

By using Thin film hydration method were prepared multi lamellar liposome containing diclofenac sodium. Diclofenac sodium, soya lecithin and cholesterol were dissolved in chloroform and methanol mixture in ratio (9:1). These above solutions pour in round bottom flask of rotary flash evaporator. In rotary flash evaporator the organic solvent evaporates at $60^{\circ} \mathrm{c}$, for $15 \mathrm{~min}$. at $90 \mathrm{rpm}$. After evaporating organic solvent thin layer which are form on inner surface of round bottom flask. These thin layers dried overnight by using vacuumed oven. Then this thin lipid layer suspension in phosphate buffer saline (PBS) having PH-7.4 by vertexing for $10 \mathrm{~min}$.and then it was allowed to hydrate for $1 \mathrm{hr}$ at $70^{\circ} \mathrm{C}$, $90 \mathrm{rpm}$. Then this liposomal suspension centrifuge by using ultra-centrifugation Machin at $3000 \mathrm{rpm}$ for $30 \mathrm{~min}$. Then the settle liposome again centrifuge in PBS. Then this suspension of liposome sonicates for $15 \mathrm{~min}$ at $65^{\circ} \mathrm{C}$ to get small unilamellar vesicle (SUV). ${ }^{5}$ For this study the four batches were prepared and formula and their composition are show in below table:

Table 2: Composition of Diclofenac sodium liposome

\begin{tabular}{|c|c|c|c|c|}
\hline Sr.No. & Batch Code & Amount of Drug & Soya Lecithin & Cholesterol \\
\hline 1. & F1 & $25 \mathrm{mg}$ & $100 \mathrm{mg}$ & $15 \mathrm{mg}$ \\
\hline 2. & F2 & $50 \mathrm{mg}$ & $100 \mathrm{mg}$ & $15 \mathrm{mg}$ \\
\hline 3. & F3 & $75 \mathrm{mg}$ & $100 \mathrm{mg}$ & $15 \mathrm{mg}$ \\
\hline 4. & F4 & $100 \mathrm{mg}$ & $100 \mathrm{mg}$ & $15 \mathrm{mg}$ \\
\hline
\end{tabular}

\section{Characterization of Dliclofenac Sod. Liposome:}

\section{Particle size: -}

The particle size of liposome is generally taken by zeta sizer instrument. This instrument containing Malvern PCS software. Before taking the result of sample solution the sample must be diluted with distilled water. The distilled water not interferes with result. Then after dilution the result were taken. The particle size must be required in nano range some time it goes to micron range if multilamellar vesicle are present. This software was taken the average particle size of liposome. The particle size of sample solution was determined by using light scattering technique and by transmission electron microscope. If the particle size of liposome increases then decrease the uptake and bioavailability of drug. The analysis of particle size was carried out for $60 \mathrm{~s}$ at $165^{\circ} \mathrm{C}$ scattering angle of detection. The particle size is most important, the particle size of liposome in nano range are having more effective drug delivery as compare to micron range. The one advantage of large particle size liposome is having more area to fill more drug but it has very slow-release pattern. Various method is used 
for administration of particle size of liposome such as SEM, TEM, XRD, AFM, Dynamic light scattering (DLS). 6,7,8,9.10

PDI: -

PDI is also called "particle size distribution". If the sample having very broad size distribution then poly dispersed value goes to more than 0.7 . The PDI of liposome is also obtained by photon Correlation spectroscopic analysis. During formulation of liposome the effort of manufacturer are must be to achieve lowest PDI value.[16]

\section{Zeta Potential: -}

The zeta potential means the charges which are present on the surface of liposome. The many time the charge is present on the surface of liposome. This charge is come due to the component or ingredient which was used during the manufacturing. Some charge is must be required on surface of all liposome present in formulation, due to some charge all liposome particle repeal to each other and coagulation of particle are avoided. The zeta potential of liposome was taken in zeta sizer instrument having Malvern software. The analysis of sample was carried out at $25^{\circ} \mathrm{C}$ with the angle of detection $90 \circ$. The ideal zeta potential value must be required in range between +30 to $-30 \mathrm{mV}$. These ranges prevent the aggregation of liposomal particle. 11,12,14

\section{Entrapment Efficiency:}

For determination of drug entrapment, the amount of drug present in the clear supernatant after centrifugation was determined $(w)$ by UV spectrophotometer at $254 \mathrm{~nm}$. A standard calibration curve of drug was plotted for this purpose. The amount of drug in supernatant was then subtracted from the total amount of drug added during the preparation (W). Effectively, (W-w) will give the amount of drug entrapped in the liposome. 13,15,17,18,20

$$
\% \text { Drug Entrapment }=(\mathrm{W}-\mathrm{w} / \mathrm{W}) \times 100
$$

\section{Loading Efficiency:}

Drug content in the preparation was determined by extracting drug from the liposome with $0.1 \mathrm{M}$ hydrochloric acid. In this method liposome (50mg) were stirred in $50 \mathrm{ml}$ hydrochloric acid until dissolved. It was filtered by Millipore filter paper and drug content was determined, after suitable dilution. At $254 \mathrm{~nm}$ by UV spectroscopy. The loading efficiency (L) of the liposome was calculated according to following formula.

$$
\mathrm{L}(\mathrm{C} / \mathrm{C})(\mathrm{Qn} / \mathrm{Wn}) \times 100
$$

Were, $\mathrm{Qn}$ is the amount of drug present in Liposome and $\mathrm{Wn}$ is weight of liposome.19

\section{In vitro drug release: -}

The Diclofenac sodium liposome was present in aqueous suspension they separated by using ultracentrifugation. Then 2mg of Diclofenac sodium liposome was taken and dispersed in 10ml 7.4-phosphate buffer. After this $10 \mathrm{ml}$ solution place in dialysis membrane bag. Then make $900 \mathrm{ml}$ 7.4 phosphate buffer and add it in dissolution apparatus beaker. Make the temperature $37^{\circ} \mathrm{C}$. For the dissolution the USP paddle was used. At appropriate time intervals $1 \mathrm{~mL}$ of the release medium was removed and $1 \mathrm{~mL}$ fresh 7.4 phosphate buffer solution was added in to the system. The amount of Diclofenac sodium in the release medium was estimated by UV-Visible Spectrophotometer at $275 \mathrm{~nm} .{ }^{21}$

\section{RESULT AND DISCUSSION}

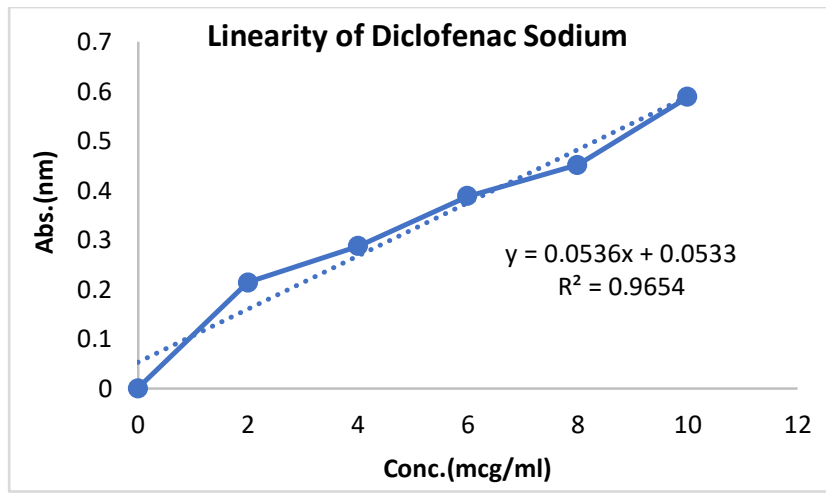

Graph 1: Linearity of Diclofenac sodium

\section{Particle size: -}

The particle size of liposome Increases by increasing the concentration of drug. In F1 batch the particle size occurs about $796.2 \mathrm{~nm}$. Then final observation is as concentration of diclofenac increase then particle size is also increase. Very slightly particle size change occurs in all batches. The batch F3 shows the particle size about $836.4 \mathrm{~nm}$.

\begin{tabular}{|c|c|c|c|c|c|}
\hline Z-Average (d.nm): & 836.4 & Peak 1: & $\begin{array}{l}\text { Size (d.nm): } \\
868.6\end{array}$ & $\begin{array}{l}\% \text { Intensity } \\
96.9\end{array}$ & $\begin{array}{l}\text { Width (d.nm): } \\
289.7\end{array}$ \\
\hline Pdl: & 0.369 & Peak 2: & 5385 & 3.1 & 319.6 \\
\hline Intercept: & 0.973 & Peak 3: & 0.000 & 0.0 & 0.000 \\
\hline
\end{tabular}

Results

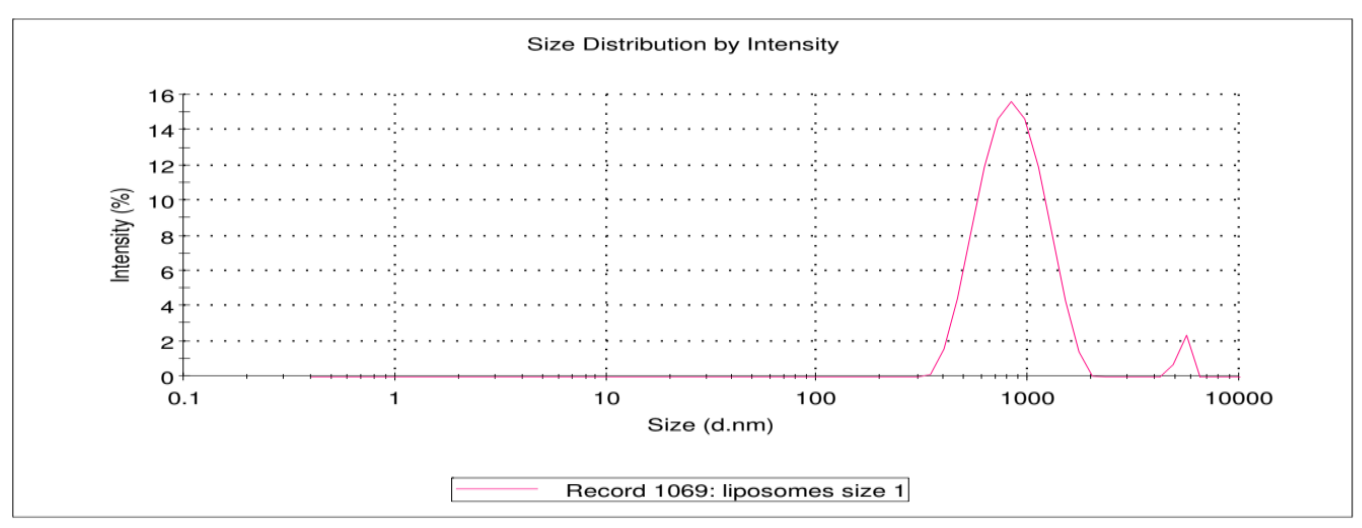


Zeta Potential: -

\section{Results}

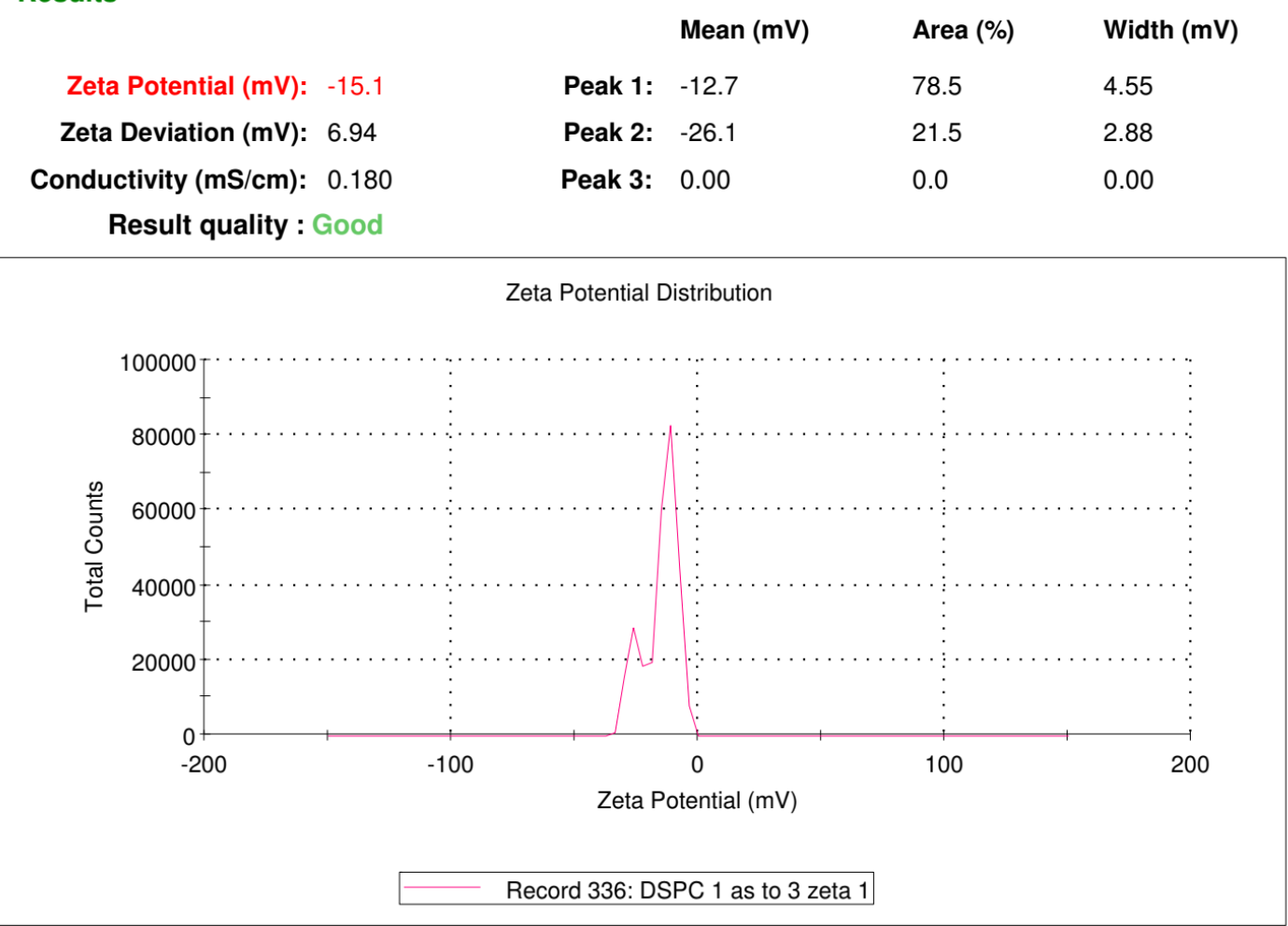

The zeta potential is most important Evaluation parameter. There are many drugs which are affecting the zeta potential value of liposome. Due to some drug means those drugs incorporated in liposomes which are causes the charge on the surface of liposome. Here in this work also observed that as amount of Diclofenac sodium increases then zeta potential also increases. If zeta potential value is not in range of $-30 \mathrm{mV}$ to $+30 \mathrm{mV}$ then the aggregation of liposome take place in formulation.

PDI: -

In this work only concentration of drug change as per batches. As the amount of drug increase in each batch the PDI also increase, but in batch F4 the PDI value decrease. PDI values are must be required below the 0.7 and this obtained all PDI value below 0.7 .

\section{Entrapment Efficiency:}

The entrapment efficiency is also important evaluation parameter foe liposome. Entrapment efficiency of all batches occur different such as F1 is 93.64, F2is 94.86, F3 is 96.04 and F4 is $96.22 \%$.

\section{Loading Efficiency:}

The loading efficiency also varies according to different drug concentration, such as in batch F1 is $4.2, \mathrm{~F} 2$ is $5.66, \mathrm{~F} 3$ is 7.41 and in $\mathrm{F} 4$ is $8.41 \%$.

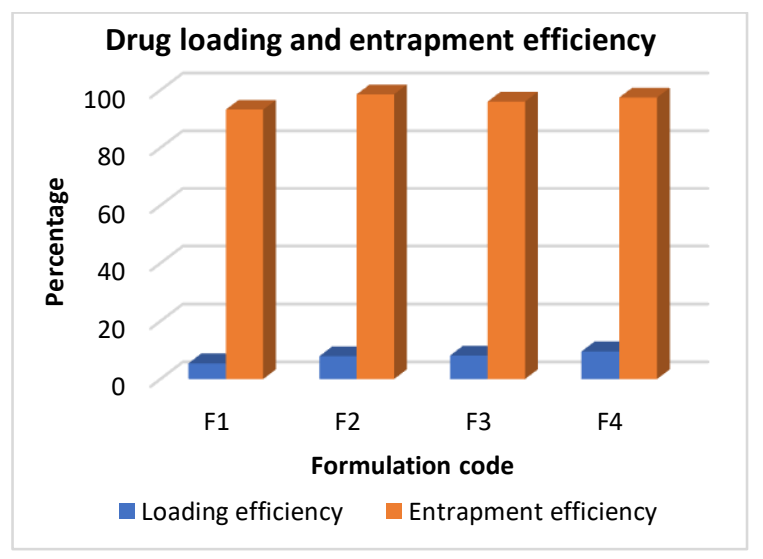

Graph 2: Effect of drug and polymer on Loading efficiency and Entrapment efficiency

Table-3: - Evaluation Parameter of Liposome

\begin{tabular}{|c|l|l|l|l|l|}
\hline Sr.No. & \multicolumn{1}{|c|}{ Evaluation Test } & F1 & F2 & F3 & F4 \\
\hline 1. & Entrapment Efficiency (\%) & 93.24 & 98.56 & 96.04 & 97.48 \\
\hline 2. & Loading Efficiency (\%) & 5.44 & 7.88 & 8.14 & 9.56 \\
\hline 3. & Particle Size (nm) & 796.2 & 815.4 & 836.4 & 915 \\
\hline 4. & Polydisperse Index (PDI) & 0.245 & 0.346 & 0.369 & 0.298 \\
\hline 5. & Zeta Potential (mV) & -15.4 & -21.6 & -22.3 & -27.6 \\
\hline
\end{tabular}




\section{In vitro drug release: -}

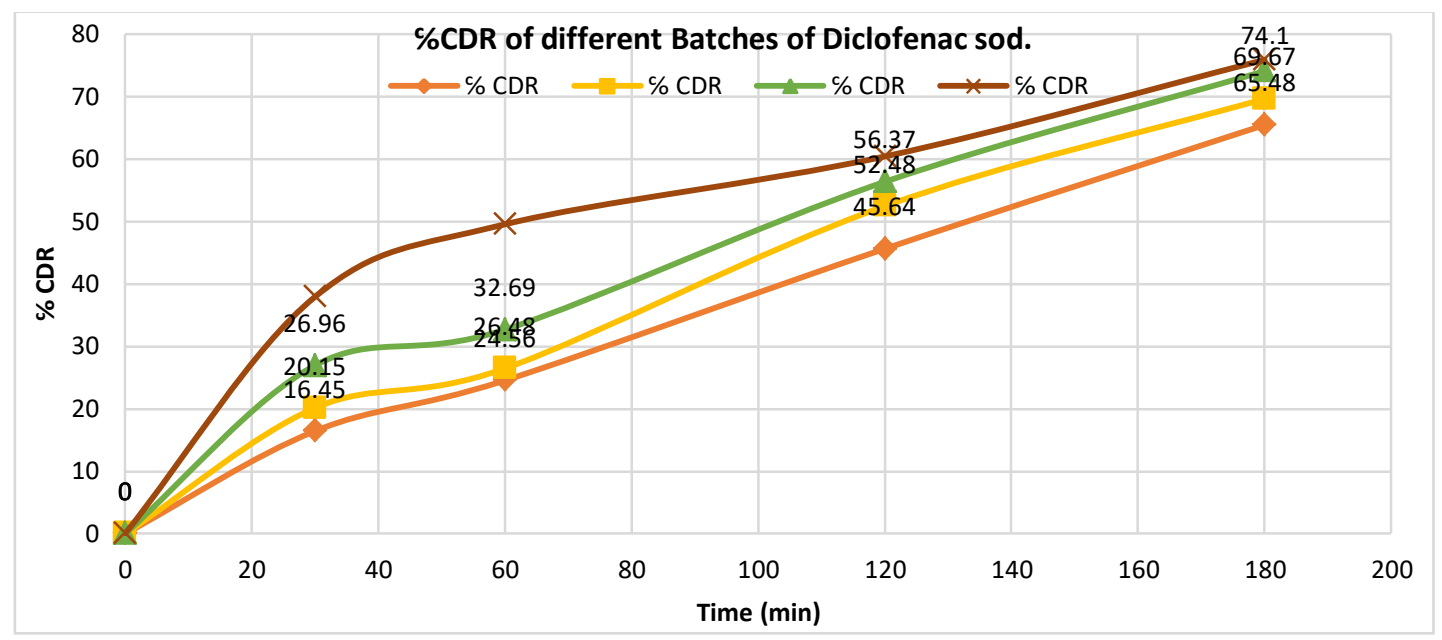

Graph-3: \% CDR of Different batches of Diclofenac sodium.

\section{ACKNOWLEDGEMENT}

I am very happy to express my deepest sense of gratitude to Dr. H.S. Mahajan and Dr. C.V Pardeshi for her valuable guidance during the course of research work without which it would have been very difficult, rather impossible task for me. He provided invaluable motivation, constructive suggestion and criticism during the course of dissertation work.

\section{CONFLICT OF INTEREST}

No conflict of interest.

\section{CONCLUSION}

Diclofenac sodium having several adverse effects. This side effect of diclofenac sodium reduces due to the liposomal formulation of diclofenac sodium. The bioavailability of diclofenac also increase's due to this novel formulation. As the concentration of drug increase's in formulation then entrapment efficiency, loading efficiency particle size of liposome and zeta potential also increase.

\section{REFERENCES}

1. Dua JS, Rana AC, Bhandari Ak. Liposome: method of preparation and application. International Journal of Pharmaceutical Studies and Research 2012; 3(2):14.

2. Akbar Zadeh A, Rezaei-Sadabady R, Davaran S, Joo SW, Zarghami $\mathrm{N}$, Hanifehpour Y, et.al. Liposome: classification, preparation, and applications. Nanoscale Research Letters 2013; 8:2.

3. Pistone S. Formulation and evaluation of polysaccharide and liposome-based nano systems for improved targeting to the oral cavity; hesis for the degree of Philosophiæ Doctor Department of Pharmaceutics. School of Pharmacy University of Oslo - Norway 2016:11.

4. Marripati S, Umasankar K, Reddy PJ. A revive on liposome. International Journal of Research in Pharmaceutical and Nano Sciences 2014; 3(3):159-60.

5. Jithan AV, Swathi M. Development of topical Diclofenac sodium liposomal gel for better anti-inflammatory activity. International Journal of Research in Pharmaceutical and Nano Sciences 2010; 3(2):986-87.

6. Lankalapalli S, Vinai Kumar Tenneti VS, Adama R. Preparation and evaluation of liposome formulations for poorly soluble drug itraconazole by complexation. Scholars Research Library der Pharmacia Letter 2015; 7(8):3.

7. Moghimipour E, Salami A, Monjezi M. Formulation and Evaluation of Liposomes for Transdermal Delivery of Celecoxib. Jundishapur J Nat Pharm Prod 2015; 10(1):2-3.
8. Jadhav MP, Nagarsenker MS, Gaikwad V, Samad A, Kshirsagar NA. Formulation and Evaluation of Long Circulating Liposomal Amphotericin B: A Scinti-kinetic Study using 99mTc in BALB/C Mice. Indian Journal of Pharmaceutical Sciences 2011; 73(1):5764

9. Shivhare UD, Ambulkar DU, Mathur VB, Bhusari KP, Godbole MD. Formulation and evaluation of Pentoxifylline Liposome formulation. Digest Journal of Nanomaterials and Biostructures 2009; 4(4):859-62.

10. Umbarkar M.G. Rindhe P.S. Chandrawanshi S. Formulation and Evaluation of Polymeric nanoparticle by nanoprecipitation method. Journal of drug delivery and therapeutics 2020; 10(5s):136-142.

11. Patel RP, Patel H, Baria AH. Formulation and Evaluation of Liposomes of Ketoconazole. International Journal of Drug Delivery Technology 2009; 1(1):18.

12. Subash Chandran MP, Pandey VP. Formulation and evaluation of gliclazide loaded liposomes. Scholars Research Library der Pharmacia Letter 2016; 8(11):63-64.

13. Ghule MM, Bhoyar GS. Formulation and Evaluation of modified liposome for transdermal drug. Journal of Developing Drugs 2018; 7(1):2-3.

14. Latha K, Lalitha P, Nasseb Basha SK. Formulation and Evaluation of Darifenacin Hydrobromide Nano-Liposomes. Journal of Chemical and Pharmaceutical Research 2017; 9(8):174-76.

15. De A, Nagaswamy Venkatesh D. Design and evaluation of liposomal delivery system for L-Asparaginese. Journal of Applied Pharmaceutical Science 2012; 2(8):112-17.

16. Song J, Shi F, Zhang Z, Zhu F, Xue J, Tan X, et.al. Formulation and Evaluation of Celastrol-Loaded Liposomes. Molecules 2011; 16:7888.

17. Vijay kumar M.R, Abdul hasan sathali A, Arun.k. Formulation and Evolution of diclofenac potassium ethosome. International Journal of Pharmacy and Pharmaceutical Sciences 2010; 2(4):83.

18. Sharma S, Sharma A. Development, Formulation, characterization and evaluation of elastic liposomal formulation of chlorzoxazone for transdermal delivery. International Journal of Therapeutic Applications 2012; 2:15.

19. Ibrahim Abd-Allah F. Development, Characterization and Ex vivo Evaluation of Various Liposome-encapsulated Aceclofenac Formulations. British Journal of Pharmaceutical Research 2016; 9(4):7.

20. Sailor G, Seth AK, Parmar G, Chauhan S, Javia A. Formulation and in vitro evaluation of berberine containing liposome optimized by 32 full factorial designs. Journal of Applied Pharmaceutical Science 2015; 5(7):24-25.

21. Sangeetha SS, Karki R. Formulation and evaluation of liposomes in Carbopol gels for mixed vaginal infections. Scholars Research Library der Pharmacia Letter 2015; 7(5):293.

22. Jino Nesalin JA, Gowthamrajan K, Somasekhara CM. Formulation and Evolution of Nanoparticles containing Flutamide. International Journal of Chemtech Research 2009; 1(4):1332. 